\title{
Cuticular Cracking on Nectarine Fruit Surface: Spatial Distribution and Development in Relation to Irrigation and Thinning
}

\author{
Caroline Gibert \\ INRA, Unité Plantes et Systèmes de culture Horticoles, UR 1115, Domaine Saint Paul, Site Agroparc, \\ Avignon Cedex 9, F-84914, France \\ Joël Chadouf \\ INRA, Unité de Biométrie, UR 546, Domaine Saint Paul, Site Agroparc, Avignon Cedex 9, \\ F-84914, France \\ Gilles Vercambre, Michel Génard, and Françoise Lescourret ${ }^{1}$ \\ INRA, Unité Plantes et Systèmes de culture Horticoles, UR 1115, Domaine Saint Paul, Site Agroparc, \\ Avignon Cedex 9, F-84914, France
}

\begin{abstract}
AdDitional INDEX WORDS. cuticular cracks, fruit growth, stratified sampling, crop load, irrigation
ABSTRACT. Investigations on "natural" cuticular cracks were conducted on nectarine fruit [Prunus persica (L.) Batsch var. nucipersica (Suckow) C.K. Schneid.]. A method for quantifying the cuticular crack surface area on a whole fruit basis was proposed. By using a stratified sampling design, the spatial distribution of the cuticular cracks over three regions (stylar end, peduncle, and cheek), their morphology, and the estimation of the total proportion of cuticular cracks on the fruit were studied. These features were examined during fruit development and in response to several fruit growing conditions corresponding to various crop loads and irrigation regimes. Cuticular cracks on nectarine fruit occurred during the final rapid fruit growth stage. Larger fruit presented higher cuticular crack densities in the apical regions than in the cheek regions. Thin and larger cuticular cracks occurred continuously during fruit development. Cuticular cracks represented $10 \%$ to $12.5 \%$ of the fruit surface area for well irrigated or low crop load trees, whereas they covered less than $4.5 \%$ for the heavy crop load and water deficit treatments. Cheek regions largely contributed to the total cuticular crack surface area $(>60 \%)$, regardless of the fruit growing conditions. After irrigation was restricted, cuticular crack development was limited. A positive relationship was established between the cuticular crack surface area per fruit surface area and the fruit fresh weight.
\end{abstract}

Cuticular cracks may be defined as the physical failure of the fruit skin (Milad and Shackel, 1992). They form shallow or deeper oblong wounds on fruit (Nguyen-The, 1991; Sekse, 1998). In addition to having a negative affect on fruit appearance, they may also influence organoleptic quality, particularly by accelerating softening due to water loss (Beyer et al., 2002; Glenn and Poovaiah, 1989). At the same time, they are considered as preferential entry sites for fungi pathogens, such as Monilinia (Aderh. \& Ruhl.) species (Børve et al., 2000; NguyenThe et al., 1989). Therefore, cuticular cracks create storage problems worldwide for several commercial fruit crops, such as tomato [Lycopersicon esculentum Mill. (Peet, 1992)], bell pepper [Capsicum annuum L. (Aloni et al., 1998)], sweet cherry [Prunus avium L. (Peschel and Knoche, 2005; Sekse, 1995)], apple [Malus domestica Borkh. (Opara and Tadesse, 2000; Opara et al., 2000)], and nectarine (Nguyen-The et al.,

Received for publication 19 Oct. 2006. Accepted for publication 2 Feb. 2007. This research was supported by grants from the French Ministry of Ecology and Sustainable Development program, "Evaluation and Reduction of Risks Related to Pesticide Use" (12-E/2003 CV 300099), and from the "Irriqual" program, co-funded by the European Commission, DG Research, within the 6th Framework Program of RTD, Priority 5-Food Quality and Safety (FP6-FOODCT-2006-023120).

We gratefully acknowledge P. Rouet for his assistance in the field experiments and $\mathrm{G}$. Wagman for having proofread our manuscript.

${ }^{1}$ Corresponding author. E-mail: lescou@avignon.inra.fr.
1989). Cuticular cracks could therefore lead to severe economic losses for fruit growers (Jobin-Lawler, 2005).

Several factors contribute to fruit cracking and are often in interaction. Indeed, the unbalanced water flux into and out of the fruit (Opara et al., 1997) could result in the increase of internal pressure and the maximal elastic limit of the cuticle could thus be exceeded (Ohta et al., 1997). Similarly, microcracks on sweet cherry fruit were shown to be related to the strain of the cuticular membrane induced by fruit growth and surface area expansion in the absence of cuticular membrane deposition (Knoche and Peschel, 2006; Knoche et al., 2004; Peschel and Knoche, 2005). Moreover, several studies pointed out that by hydrating isolated cuticles, their susceptibility to fracture increased, thereby indicating that water or surface wetness may play a direct role in fruit cuticular cracking (Knoche and Peschel, 2006; Matas et al., 2005; Petracek and Bukovac, 1995; Wiedemann and Neinhuis, 1998). Cultural practices such as pruning, fruit thinning, and irrigation could promote the occurrence of cuticular cracks by acting on fruit growth, its water balance, and cuticle strain. Orchard management practices such as frequent irrigation and low crop density were shown to contribute to the increase in stem and calyx-end splitting on prunes (Prunus domestica L.) and apples (Milad and Shackel, 1992; Opara and Tadesse, 2000). Peet and Willits (1995) showed a higher percentage of cracked tomatoes grown in greenhouses as a result of excess watering. 
These qualitative investigations were based either on estimated frequencies of cracked fruit after fruit immersion (Christensen, 1972, 1973; Glenn and Poovaiah, 1989), on cracking indices often concentrated on a preferential region of cuticular crack occurrence [e.g., stylar end (Bakker, 1988)], or on frequencies of microcracks on exocarp segments (Knoche and Peschel, 2006; Peschel and Knoche, 2005). However, few studies have quantified the cuticular crack surface area on the whole fruit by considering the large variability of crack occurrence over the regions (cheek, stylar end, and peduncle). Such quantitative measurements could be used to identify the exact contribution of cuticular cracks on fruit surface conductance to water vapor diffusion and to evaluate the sensitivity of fruit surface area to pathogen entry.

In this study, we aimed at measuring the "natural" crack surface area on nectarine skin sampled over three distinct regions (stylar end, peduncle, and cheek), using a stratified sampling design. Firstly, the spatial distribution of cuticular cracks over these three regions was depicted in relation to time and growing conditions. Cuticular cracks were then described from a morphological point of view. Finally, the total cuticular crack surface area per fruit surface area was characterized in relation to time, growing conditions, and fruit fresh weight. For these purposes, experiments were performed in 2004 and 2005 on 'Zephir' nectarine fruit, with various irrigation regimes and crop loads, to obtain contrasting fruit growth curves and several levels of cuticular cracking.

\section{Material and Methods}

Plant material and experimental design. Experiments were conducted in 2004 and 2005 on 'Zephir' nectarine trees (late-maturing cultivar), grafted on Grande-Ferrade 305 (GF305) rootstock for orchard-grown trees and on GrandeFerrade 677 (GF677) rootstock for container-grown trees, at the National Institute of Agronomical Research (INRA) in Avignon (southeastern France, lat. $43^{\circ} 9^{\prime} \mathrm{N}$, long. $4^{\circ} 8^{\prime} \mathrm{E}$ ). Trees were goblet-trained and received routine horticultural care, including winter pruning, daily irrigation by microjet sprinklers (orchard) or by drip irrigation (containers), and pest control.

Fruit growing conditions varied as a result of different irrigation regimes and crop loads, yielding a total of six treatments. Development time was expressed in days after full bloom (DAFB).

In 2004 and 2005, two experiments were performed on 20 trees planted in 1998 (trunk cross-sectional area $=38 \mathrm{~cm}^{2}$ ). The first experiment was performed in 2004, from 23 to 150 DAFB (22 Mar. 2004), where high (HC-04) and low crop load (LC-04) were applied at 42 DAFB with 400 and 120 fruit per tree, respectively. Each treatment was composed of 10 trees. From the beginning to the end of the study, $11.25 \%$ (HC-04) and $37.5 \%$ (LC-04) of the fruit crop load per tree was removed for sampling.

In 2005, from 25 to 151 DAFB (28 Mar. 2005), two levels of crop loads were applied at 37 DAFB on 10 trees per treatment. For the high crop load trees (HC-05) and for the low crop load trees (LC-05), 1000 and 120 fruit per tree were left on, respectively. From the beginning to the end of the study, $4 \%$ (HC-05) and 25\% (LC-05) of the fruit crop load per tree was removed for sampling.

A third experiment was performed in 2005, from 24 to 125 DAFB (29 Mar. 2005), on 20 trees planted in 2002 (trunk crosssectional area $=10 \mathrm{~cm}^{2}$ ) and cultivated outdoors in $110-\mathrm{L}$ containers. The trees were thinned to 55 fruit per tree at 38 DAFB. Two drip-irrigation regimes were applied from 99 DAFB. Ten trees were well irrigated (WI), and 10 trees were water-restricted [water deficit (WD); Fig. 1]. The amount of water per tree per day was applied using eight cycles of irrigation per day. The total amount applied per tree over the season was $1022.28 \mathrm{~L}$ (WD tree) and $1365.40 \mathrm{~L}$ (WI tree). Irrigation was controlled by fruit diameter changes measured using linear variable differential transducers $\left(10^{-1} \mu \mathrm{m}\right.$; Solartron Metrology, Elancourt, France) that were installed on nectarine fruit (one per tree) and on trunks (three per treatment). The WD trees received $50 \%$ of the water amount applied to the WI trees from 99 to 108 DAFB and 30\% from 108 to 125 DAFB. Mean predawn water potentials, from 108 to $125 \mathrm{DAFB}$, were equal to -0.34 and $-0.37 \mathrm{MPa}$ for WI treatment (for fruit-bearing shoots and leaves, respectively) and to -0.62 $\mathrm{MPa}$ for WD treatment (for both organs). Mean midday water potentials, from 108 to $125 \mathrm{DAFB}$, were equal to -1.01 and $-1.82 \mathrm{MPa}$ for WI treatment and to -1.86 and $-2.14 \mathrm{MPa}$ for WD treatment (for fruit-bearing shoots and leaves, respectively). From the beginning to the end of the study, $\approx 50 \%$ of the fruit crop load per tree was removed for sampling.

Fruit Growth. The fruit growth was determined by measuring cheek diameter with a digital caliper gauge $\left(10^{-5} \mathrm{~m}, 500-\right.$ 181 U; Mitutoyo, Roissy, France). For the first experiment, 100 fruit per treatment were measured twice per week; for the second and the third experiments, 150 and 100 fruit per treatment were measured once a week, respectively. In situ fruit fresh weight was calculated for each treatment on the basis of allometric relationships between the cheek diameter $[D$ (millimeters)] and the fresh weight $[M$ (grams)] of fruit that were used for conductance measurements.

$$
M(t)=\alpha \times D(t)^{\beta}
$$

with $\alpha$ (ranging from 0.0029 to 0.0051 ) and $\beta$ (ranging from 2.46 to 2.61 ) specific to each experiment. This relationship

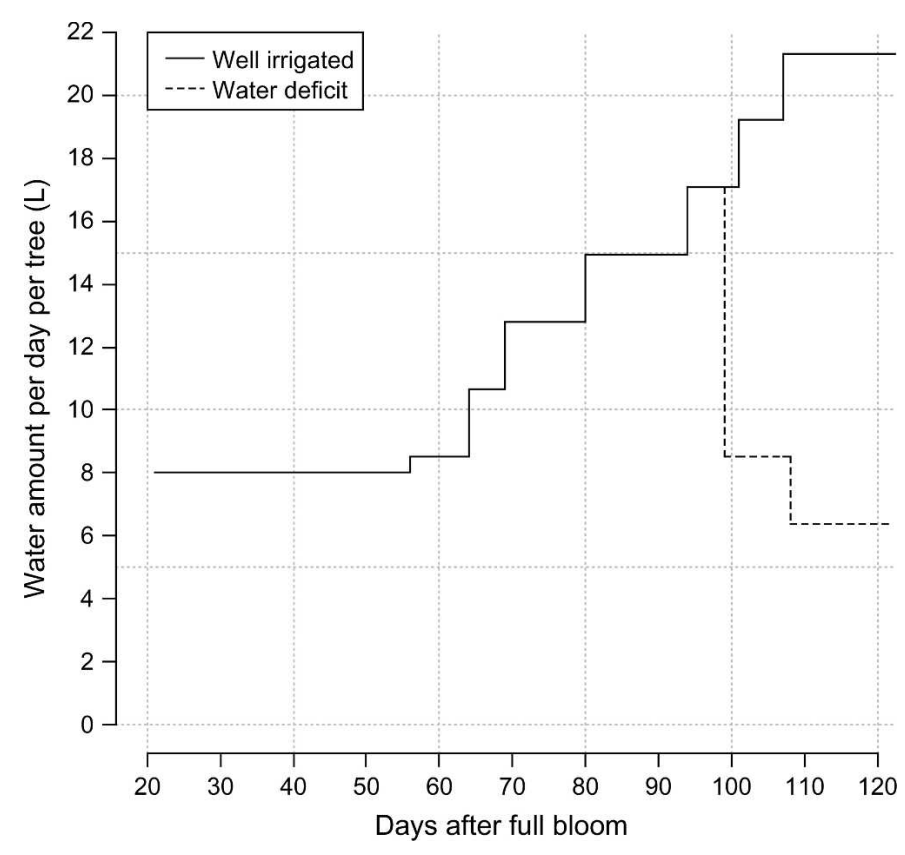

Fig. 1. Evolution of the amount of water per day applied per 'Zephir' nectarine container-grown tree in 2005. 
assumes that fruit density equals 1 and remains constant during development.

STRATIFIEd SAMPling METHOD FOR STUdying THE CRACK SURFACE AREA ON FRUIT. Five fruit per treatment were harvested once a week from the beginning of each experiment. Fruit were weighed and their three diameters were measured (cheek diameter, suture, and height) to calculate fruit surface area. Dye was applied to the fruit skin (solution of toluidine blue at $0.1 \%$ ), and the fruit was rinsed and blotted (Nguyen-The, 1991). The cuticular cracks were stained dark blue, creating a strong contrast with the nectarine epidermis and enabling image analysis of the cracks. The cuticular crack observations were performed with a stereoscopic microscope $(50 \times$ magnification; Leica, Solms, Germany) and pictures were taken with a digital camera (PowerShot S50; Canon, Uxbridge, England), which was adjusted to the stereoscope by a lens $(1 \times$ magnification $)$. A micrometer slide was used to scale the picture.

Pictures were analyzed using Image Tool (version 3.0 for Windows; University of Texas Health Science Center, San Antonio, TX). Each picture was processed to separate the three components (red, green, and blue). Using the red component picture (or sometimes the green one when the contrast was greater), a manual threshold was applied, making it possible to distinguish the cuticular cracks from the epidermis and enabling the estimation of the cuticular crack geometry (surface area, perimeter, major axis length, and minor axis length).

To estimate the ratio of the surface area of cracks to the total fruit surface area, we used a stratified sampling. The surface area of a given fruit was referred to as $A_{\text {tot }}(F)$. Three zones were distinguished: peduncle, cheek (including the suture), and stylar end (Fig. 2), and their respective areas were referred to as $A_{\text {tot }}\left(Z_{z}\right)(z=1,2,3)$. Zones were assumed to be heterogeneous with respect to crack occurrence.

Zones 1 and 3 were broken down into four subzones (designated $j$, with $j$ ranging from 1 to 4 ). The surface area of each subzone was referred to as $A_{\text {tot }}\left(Z_{z, j}\right)$. For a given subzone, pictures were taken and each picture (designated $i$ ) had the same surface area, $A_{\text {tot }}\left(Z_{z, j, i}\right)$. Sampling on the nectarine cheek $(z=2)$ was slightly different. The surface area of Zone 2 was

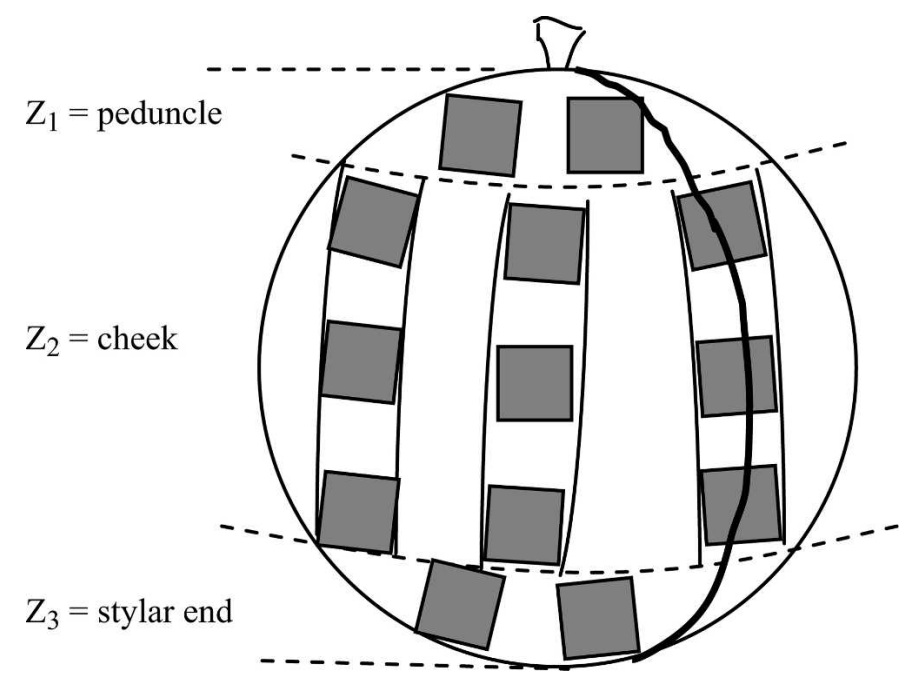

Fig. 2. Schematic representation of the three main zones of a nectarine fruit (peduncle, cheek including the suture, and stylar end). Some examples of the observed subzones are represented in gray [each square represents $8 \mathrm{~mm}^{2}$ (figure not to scale)]. The bold line symbolizes the suture. subdivided into $\approx 12$ vertical subzones. Six subzones (designated $j$ ) were chosen and corresponded to the suture, the right cheek on the suture (two subzones), the opposite suture, and the left cheek on the suture (two subzones). The surface area of each subzone was equal to $A_{\text {tot }}\left(Z_{2, j}\right)$. Pictures (designated $i$ ) were taken on the top, the equator, and the bottom of each observed cheek subzone. Their surface areas were referred to as $A_{\text {tot }}\left(Z_{2, j, i}\right)$.

The surface area of cracks on a given subzone $(j)$ of a given zone $\left(Z_{z}\right)$, referred to as $A_{\text {cutck }}\left(Z_{z, j}\right)$, was calculated as:

$$
A_{\text {cutck }}\left(Z_{z, j}\right)=\sum_{i} A_{\text {cutck }}\left(Z_{z, j, i}\right) \times \frac{A_{\text {tot }}\left(Z_{z, j}\right)}{\sum_{i} A_{\text {tot }}\left(Z_{z, j, i}\right)}
$$

Its related variance (assuming that the pictures of a given subzone were independent and identically distributed) was:

$\operatorname{var}\left(A_{\text {cutck }}\left(Z_{z, j}\right)\right)=\left(\frac{A_{\text {tot }}\left(Z_{z, j}\right)}{\sum_{i} A_{\text {tot }}\left(Z_{z, j, i}\right)}\right)^{2} \times \operatorname{var}\left(\sum_{i} A_{\text {cutck }}\left(Z_{z, j, i}\right)\right)$

The surface area of cracks over the entire cheek zone, referred to as $A_{\text {cutck }}\left(Z_{2}\right)$, was estimated as follows:

$$
A_{\text {cutck }}\left(Z_{2}\right)=\sum_{j} A_{\text {cutck }}\left(Z_{2, j}\right) \times \frac{A_{\text {tot }}\left(Z_{2}\right)}{j \times A_{\text {tot }}\left(Z_{2, j}\right)}
$$

where $Z_{2}$ is the cheek zone, $j$ the number of observed subzones, and $A_{\text {tot }}\left(Z_{2, j}\right)$, their surface area.

Regarding the stylar end and peduncle zones, the equation was written as:

$$
A_{\text {cutck }}\left(Z_{z}\right)=\sum_{j} A_{\text {cutck }}\left(Z_{z, j}\right)
$$

Similarly, regarding the fruit, the cuticular crack surface area would be written as:

$$
A_{\text {cutck }}(F)=\sum_{z} A_{\text {cutck }}\left(Z_{z}\right)
$$

and its variance as:

$$
\operatorname{var}\left(A_{\text {cutck }}(F)\right)=\sum_{z} \operatorname{var}\left(A_{\text {cutck }}\left(Z_{z}\right)\right)
$$

To subsequently present the mean cuticular crack surface area per fruit surface area and its SE, the calculation of the variance of the density of cuticular cracks at a given date and for a given treatment was necessary:

$$
\operatorname{var}\left(\frac{A_{\text {cutck }}}{A_{\text {tot }}}(F)\right)=\frac{1}{n_{f}-1} \times \sum_{n_{f}} \frac{\operatorname{var}\left(A_{\text {cutck }}(F)\right)}{\left(A_{\text {tot }}(F)\right)^{2}}
$$

where $n_{\mathrm{f}}$ is the number of fruit for which cuticular cracks were observed at a given date and for a given treatment.

Statistical Analysis. Data were analyzed using the R-language (version 2.2.1; Free Software Foundation, Inc., Boston, MA) "stats" package. Data were represented as mean values and SE at each measurement date. They were also described using box plots that visually display the minimum, the first quartile, the median, the third quartile, and the maximum of a data set. The density of cuticular cracks for a given zone and date between two treatments was compared using a Student's $t$ test at a significance level of 5\%. Comparisons of 
either the density of cuticular cracks between zones for a given treatment or the proportions of cuticular cracks at a given date according to the six treatments and between dates of observations for a given treatment were done by means of KruskalWallis tests at a significance level of 5\%. They were followed by a nonparametric test of multiple comparisons to identify samples that differed from each other when the hypothesis of homogeneity among samples was rejected.

Before analyzing the relationship between the cuticular crack surface area per fruit surface area $[Y$ (percent)] and the fruit fresh weight $[X$ (grams)], data were transformed with the Box-Cox method (Box and Cox, 1964) because fruit-tofruit variation increased with the mean. The Box-Cox function (R-language "mass" package) was run to find the best power transformation (parameter $\lambda$ ) of our data, and the optimal choice for $\lambda$ was 0.41 . A two-parameter curve, $Y^{\lambda}=1_{\left\{X^{\lambda} \geq a\right\}} \times b \times\left(X^{\lambda}-a\right)$, was then adjusted to transformed data using a least-squares procedure. Nested models were compared to determine whether this relationship was different according to treatments. In the simplest model, parameters $a$ ["threshold related to fresh weight above which cuticular cracks occur," $\left.\left(\mathrm{g}^{\lambda}\right)\right]$ and $b\left[(\% / g)^{\lambda}\right]$ were independent of the growing conditions. The most general model had a specific pair of parameters per growing condition, i.e., 12 parameters $\left(a_{i}\right.$ and $b_{i}, i$ varying from 1 to 6 ). Comparisons were made using likelihood-ratio tests.
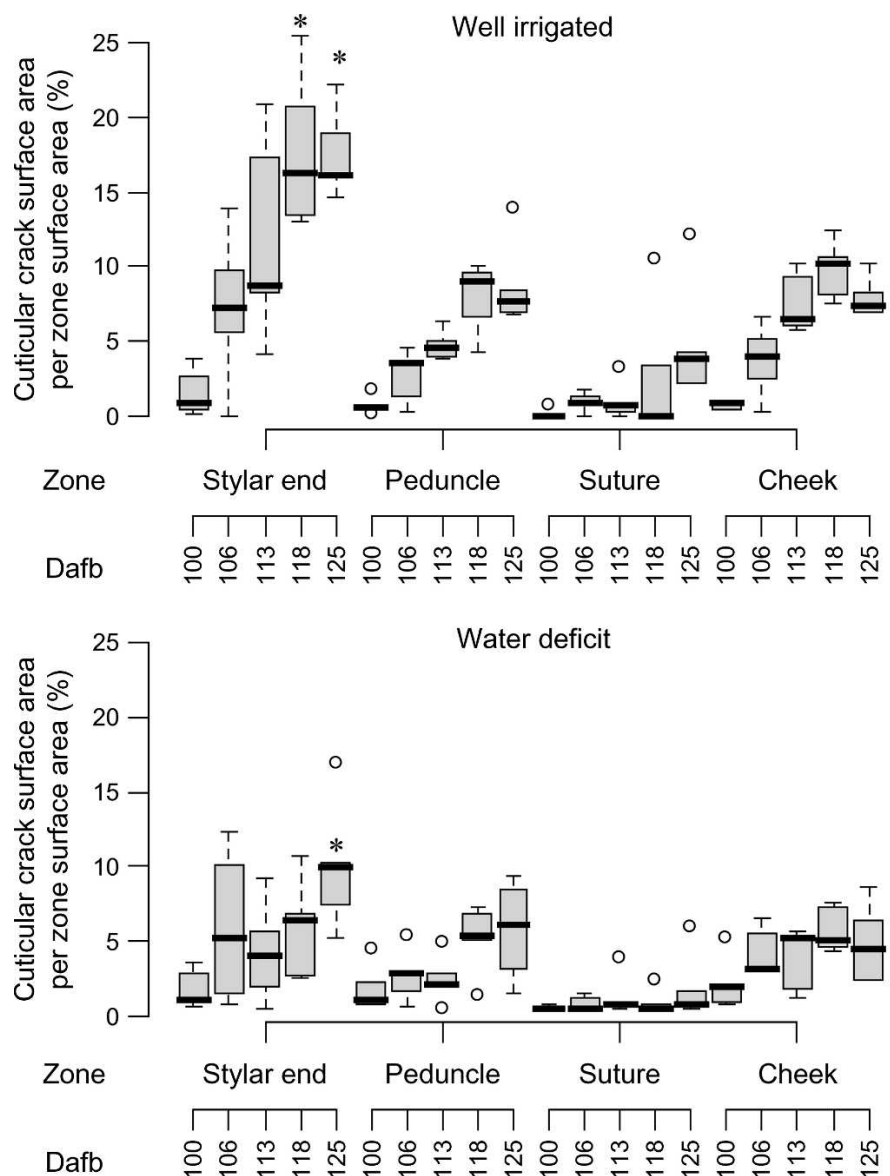

\section{Results}

SPATIAL DENSITY OF THE CUTICULAR CRACKS ON THE FRUIT IN RELATION TO TIME AND GROWING CONDITIONS. Regardless of the experimental growing conditions, the density of cuticular cracks varied with time, zones, and growing conditions (Fig. 3). The patterns shown for 2004 data on Fig. 3 were similar for both experimental years, although the level of cracking was markedly lower in 2005 (data not shown).

The density of cuticular cracks increased with time: up to $17 \%$ of the surface area of the stylar end or of the peduncle and up to $12 \%$ of the surface area of the cheek, from the beginning to the end of the observation period. When a large number of cuticular cracks were generated (WI and LC-04 treatments), the density of cuticular cracks tended to be significantly higher in the polar regions, i.e., in either the peduncle or the stylar end rather than in the cheek region. However, when few cuticular cracks were generated (WD and HC-04 treatments), the density of cuticular cracks was similar for the different zones, except for the last date of observation for which more cuticular cracks were developed on the stylar end than on the other regions. No or very few cracks occurred on the suture, regardless of the date of observation or the treatment.

The irrigation regimes affected the cracking density. The densities of cuticular cracks per zone in the WI treatment were
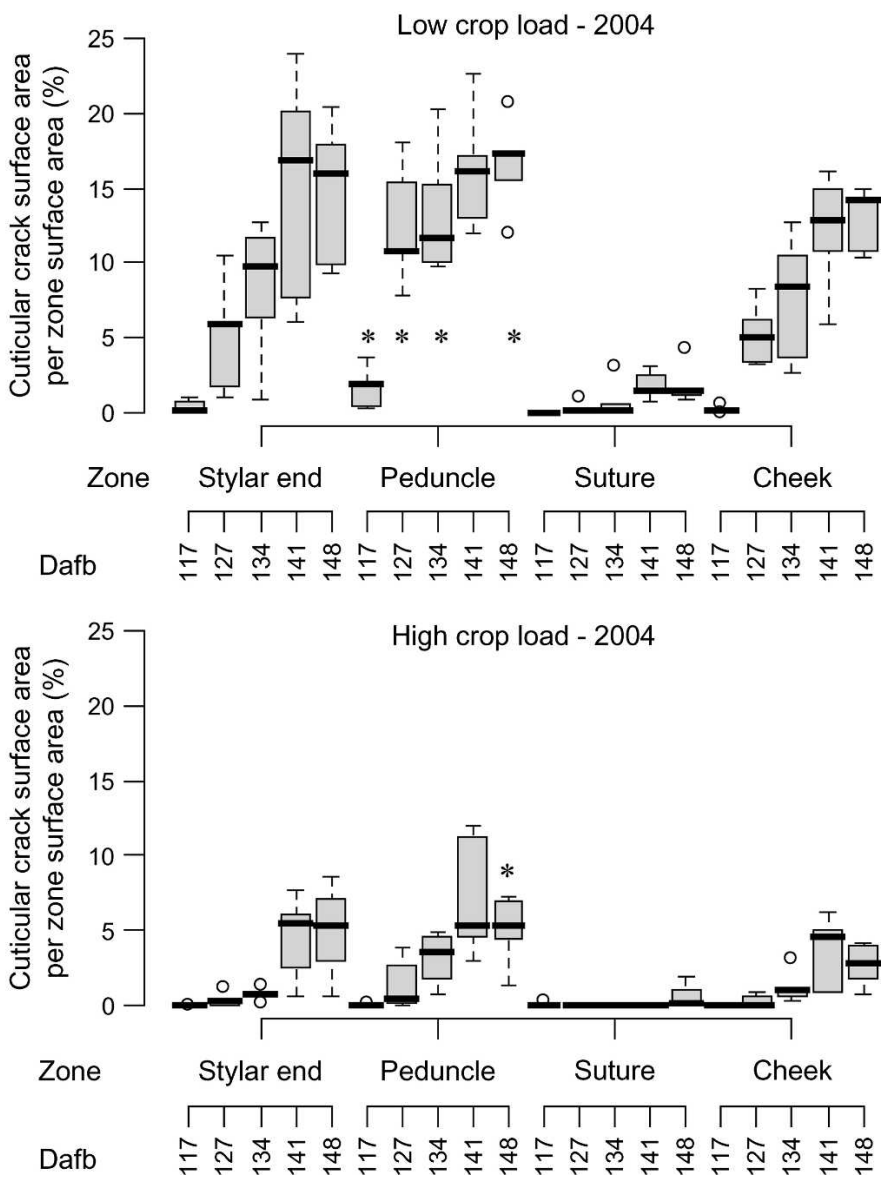

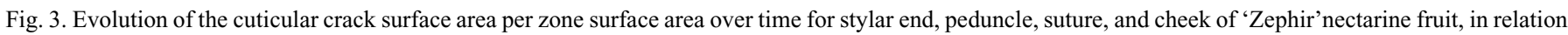
to fruit growing conditions. Box plots visually display the median (black bar), the first quartile, the third quartile (gray box), and the minimum and the maximum of a data set (extreme segments). The asterisks represent the significant nonparametric test of multiple comparisons at a significance level of $5 \%$ between zones for a given date and a given treatment. 
at least 1.5 times higher than in the WD treatment from 113 DAFB until harvest.

The fruit crop load also affected the cracking densities per zone since they were significantly higher for the LC-04 treatment than for the HC-04 treatment from 127 DAFB until harvest. Moreover, the cuticular cracks on the LC-04 treatment occurred about $10 \mathrm{~d}$ earlier than on the $\mathrm{HC}-04$ treatment.

MORPHOLOGICAL DESCRIPTION OF THE CUTICULAR CRACK SURFACE AREAS. More than $95 \%$ of the cuticular cracks had a surface area $<0.1 \mathrm{~mm}^{2}$ (data not shown); hence, the morphological description of the cuticular crack surface area distribution was restricted to this interval. The distribution of the observed cuticular crack surface areas was similar regardless of the observation dates, although the number of cuticular cracks per class differed with time (Fig. 4). Regardless of the date of observation, $>67 \%$ of the observed cuticular cracks were small, with a surface area $\leq 0.005 \mathrm{~mm}^{2}$. Larger cuticular cracks with a surface area $>0.005 \mathrm{~mm}^{2}$ developed parallel to fruit development. They represented $20 \%$ at 100 DAFB and increased to $33 \%$ at 125 DAFB.

Cuticular crack density increased with time (Fig. 5). At the beginning of cuticular crack development, most of them were thin and independent of each other. However, by the end of the experiment, there were some longer and larger cuticular cracks, as well as some even thinner ones. As can be seen on the pictures, they tended to merge as the harvest approached, leading to a cuticular crack network covering the fruit skin.

VARIATION OF CRACKING IN RELATION TO TIME AND FRUIT GROWING CONDITIONS. The treatments resulted in contrasted

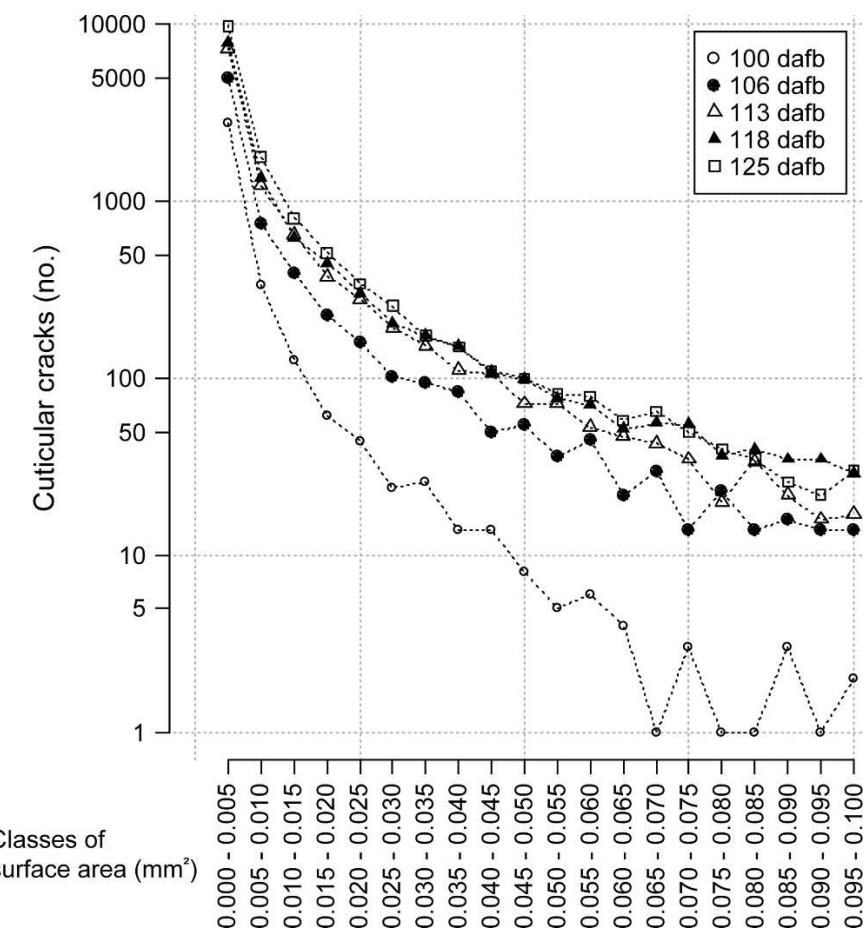

Fig. 4. Distribution of observed cuticular crack surface areas over time [in days after full bloom (DAFB)] on 'Zephir' nectarine fruit from the well irrigated treatment. Twenty classes of surface area are represented, ranging from 0 to $0.1 \mathrm{~mm}^{2}$, at intervals of $0.005 \mathrm{~mm}^{2}$. Each point represents the number of observed cuticular cracks with a surface area comprised between the indicated limits for one class. Note the log scale for the y-axis. fruit growth curves (Fig. 6). However, the general fruit growth pattern respected the double sigmoid. At harvest, the mean fruit fresh weight was maximal for the LC-04 treatment $(245.5 \pm 7.8 \mathrm{~g})$. It was moderate for the WI-05 (185.9 $\pm 3.4 \mathrm{~g}), \mathrm{LC}-05(174.4 \pm$ $5.8 \mathrm{~g}), \mathrm{HC}-04(166.4 \pm 3.5 \mathrm{~g})$, and WD-05 (154.3 $\pm 3.1 \mathrm{~g})$ treatments. It was minimal for the HC-05 treatment $(65.0 \pm$ $2.7 \mathrm{~g}$ ). Within a year, there were significant differences in fruit fresh weight between LC and HC treatments, on the one hand, and WD and WI treatments, on the other hand. Fruit from container-grown trees matured earlier ( $94 \mathrm{~d}$ for full development) than fruit from orchard-grown trees [127 d in 2004; 108 (LC-05) and $123 \mathrm{~d}$ (HC-05) in 2005 for full development].

The density of cuticular cracks per fruit varied with time and with growing conditions (Fig. 7). The density of cuticular cracks significantly and continuously increased until harvest except for the WD treatment. Indeed, for the latter, the density of cuticular crack per fruit did not significantly change with time from 106 DAFB until harvest.

There were differences in the first date of crack occurrence since the first cracks were observed at 100 DAFB on WD and WI treatments, at 117 DAFB for the LC-04 and LC-05 treatments, and at 135 and 144 DAFB for the HC-04 and HC-05 treatments, respectively. Significant differences could be observed at a given date of observation between the six growing conditions. The highest densities of cuticular crack per fruit, up to $12.5 \%$ (i.e., $20 \mathrm{~cm}^{2}$ ), were always observed on WI and on LC-04 treatments. The density of cuticular cracks per fruit on the $\mathrm{HC}-05$ was consistently the lowest. Because it represented $0.6 \%$ of the fruit at most, the cuticular cracks on those fruit were considered as negligible. The observed densities of cuticular cracks on fruit from the WD, LC-05, and HC-04 treatments were intermediate, up to $4.5 \%$ per fruit (i.e., $6 \mathrm{~cm}^{2}$ ). By restricting irrigation, the density of cuticular cracks was decreased by half. By varying the crop load, the density of cuticular cracks was at least three times lower.

The densities of cuticular cracks on fruit for low and high crop load treatments were three and seven times higher in 2004 than in 2005, respectively.

The surface area of the stylar end, the peduncle, and the cheeks represented $8 \%, 11 \%$, and $81 \%$ of the total fruit surface area, respectively (data not shown). Even if the cuticular crack density on the cheek region was similar to the apical zones, the cheeks made a larger contribution to the total cuticular crack surface area $(60 \%$ to $90 \%)$ than did the peduncle and the stylar end (5\% to $25 \%$ for the peduncle and $5 \%$ to $15 \%$ for the stylar end).

DOES CRACKING VARY WITH FRUIT FRESH WEIGHT? The density of cuticular crack data and the fruit fresh weight data were both related after being power-transformed $\left(Y^{\prime}=Y^{\lambda}\right.$ and $X^{\prime}=X^{\lambda}$, respectively; Fig. 8). It appeared that below a "threshold related to fruit fresh weight," no cuticular crack occurred. Subsequently, $Y^{\prime}$ linearly increased with $X^{\prime}$, although there was a fairly large fruit-to-fruit variation. Those results indicated that the larger the fruit was, the higher the cuticular crack density would be.

We modeled the relationship between $Y^{\prime}$ and $X^{\prime}$. For this purpose, two models were used and compared: a general model in which both parameters $a$ and $b$ (slope parameter) varied according to the six growing conditions, and a simple model with a unique series of parameters, regardless of the treatment (see Material and Methods). As the general model did not significantly improve the simplest one $(P>0.05)$, we kept the 

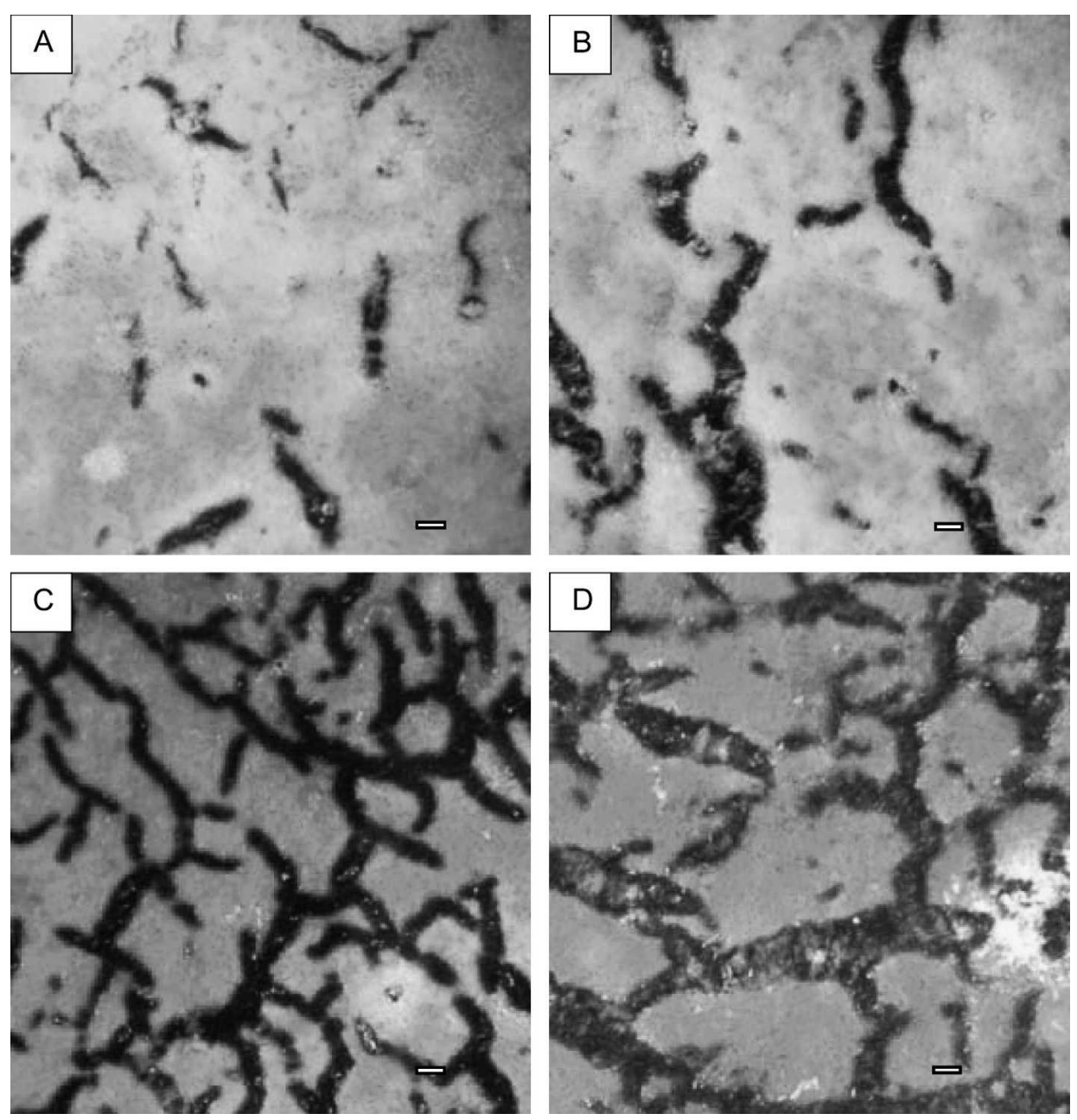

Fig. 5. (A) Thin cuticular cracks on cheek at $100 \mathrm{~d}$ after full bloom (DAFB); (B) thin and large cuticular cracks on cheek at 125 DAFB; (C, D) mixed thin and large cuticular cracks merged together on the stylar end at 125 DAFB. Bar scales, $0.1 \mathrm{~mm}$. The pictures were taken on 'Zephir' nectarine fruit from the well irrigated treatment.

regions. During its first growth period, the shape of the nectarine fruit is similar to a prolate spheroid, whereas it evolves into an oblate spheroid with fruit expansion; e.g., the average height-to-width ratio for the nectarine fruit from the LC-04 treatment was $\approx 1.65$ at 35 DAFB to 0.85 at harvest. Moreover, stylar end and peduncle regions on sweet cherry fruit surface concentrate droplets after rainfall (Verner and Blodgett, 1931), and Knoche and Peschel (2006) observed that exposure of the fruit surface to surface moisture or water vapor, by increasing the susceptibility of the cuticle to fracture (Matas et al., 2005; Petracek and Bukovac, 1995; Wiedemann and Neinhuis, 1998), resulted in the formation of cuticular cracks. Analysis of the cuticular crack surface area distribution over nectarine fruit revealed that small cuticular cracks were still continuously generated during rapid fruit growth while larger ones were developing. In addition to our pictures (Fig. 5), those observations validated the development of the cuticular cracks as a network, as suggested by Faust and Shear (1972, on apples) or Nguyen-The et al. (1989, on nectarine and peach).

Cuticular cracks on 'Zephir' nectarine fruit appeared $\approx 3-4$ weeks before harvest, regardless of the fruit growing conditions considered, as observed by Christensen (1973) and Peschel and Knoche (2005). Indeed,

simple model, whose estimated parameters were equal to 5.396 $( \pm 0.086)\left[g^{\lambda}\right]$ for $a$ and to $0.635( \pm 0.024)\left[(\% / g)^{\lambda}\right]$ for $b$. The fruit fresh weight threshold above which cuticular cracks occur would thus be equal to $61.02 \mathrm{~g}$.

\section{Discussion}

The density of cuticular cracks differed between fruit regions. It was almost null on the suture, preferentially higher on the stylar end or on the peduncle, and lower on fruit cheeks, especially for larger fruit. This is consistent with the observation that fruit cracking often occurs at the apical region of the fruit (Knoche et al., 2002; Peschel and Knoche., 2005; Sekse, 1995; Yamamoto et al., 1990). Intrinsic or abiotic factors, such as fruit shape or surface moisture, could explain our observation. Indeed, Considine and Brown (1981) outlined how the distribution of stress on the fruit surface-originating from internal turgor pressure - was a function of the fruit shape, while Yamamoto et al. (1990) showed a relationship between the distribution of stress, the degree of cracking, and the fracture patterns. In their theoretical model, Considine and Brown (1981) explained that fracturing in a prolate fruit should be longitudinal and should originate from the equator while an oblate spheroid should fracture circumferentially in the polar during early fruit growth, no cuticular cracks occurred. This observation agrees with other studies about cuticular fracturing on tomato fruit (Bakker, 1988), on 'Tasty-fruit' nectarine fruit (Nguyen-The, 1991), on 'French' prune (Milad and Shackel, 1992), and on sweet cherry fruit (Knoche et al., 2001; Peschel and Knoche, 2005). Cuticular crack development on fruit increased with days after full bloom. Christensen (1972) and Peschel and Knoche (2005) also described a higher frequency of sweet cherry fruit with microcracks as fruit grew, and Bakker (1988) reported an increasing number of cuticle cracks with tomato fruit development. The final mean proportions of cuticular cracks covering the fruit peaked at $12.5 \%$ of their surface area. The results are lower than those obtained by Bakker (1988) on tomato fruit where russeting reached $20 \%$ of the total fruit surface area but similar to the estimation of Veraverbeke et al. (2003) on 'Elstar' and 'Jonagold' apples. Such a density of cuticular cracks impairs the barrier function of the cuticle, exposing it to invasion of microorganisms such as Monilinia laxa (Aderh. \& Ruhl.) (Børve et al., 2000; Nguyen-The et al., 1989).

Cuticular crack development on fruit varied according to the fruit growing conditions. Frequent and high levels of irrigation cycles on 'Zephir' nectarine trees strongly increased the density of cuticular cracks on fruit by comparison with the 


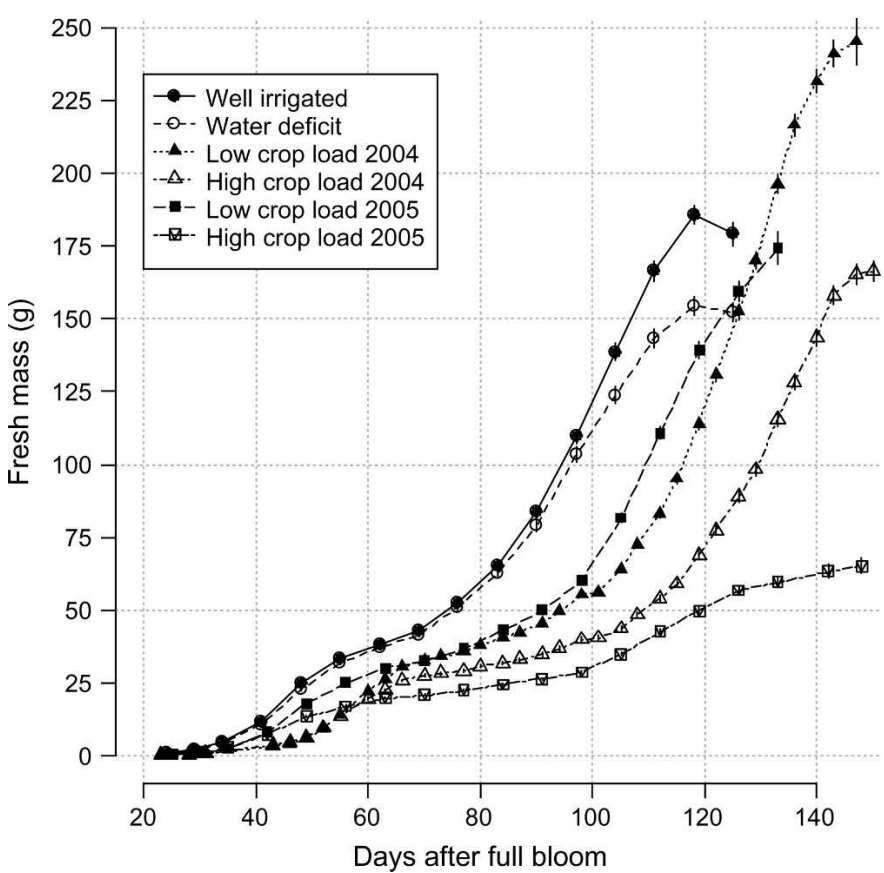

Fig. 6. Mean values of fruit fresh weight of 'Zephir' nectarine fruit according to fruit growing conditions over time. Points represent the average per date, and segments represent the corresponding SE.

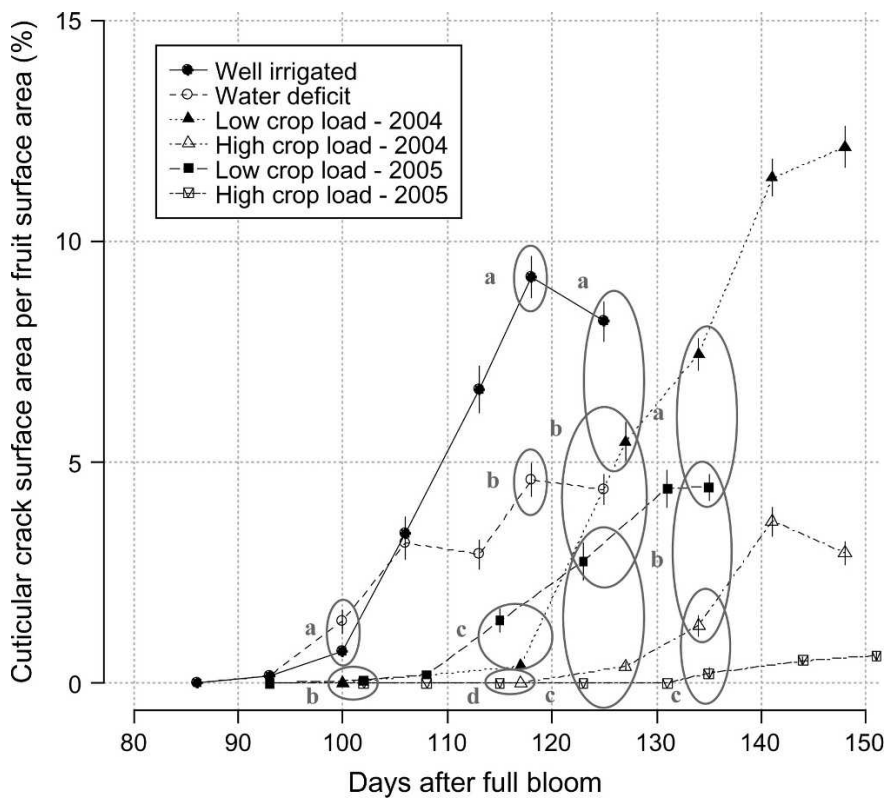

Fig. 7. Mean values of cuticular crack surface area per nectarine fruit surface area ('Zephir') for six experimental data sets in relation to days after full bloom (DAFB). Letters and ellipses indicate significant differences at the 5\% level of the Kruskal-Wallis tests and the nonparametric tests of multiple comparisons between treatments and for one period of observation. Comparisons were performed at four dates of observation $(\approx 100,117,125$, and 135 DAFB). Points represent the mean value for an observation date, and segments represent the corresponding SE.

water-restricted nectarine trees that received two- to threetimes less water per day. Indeed, by restricting the amount of water from 99 DAFB until harvest, the cuticular crack surface area per fruit surface area on fruit decreased by $49 \%$, and their development was stopped because no significant difference

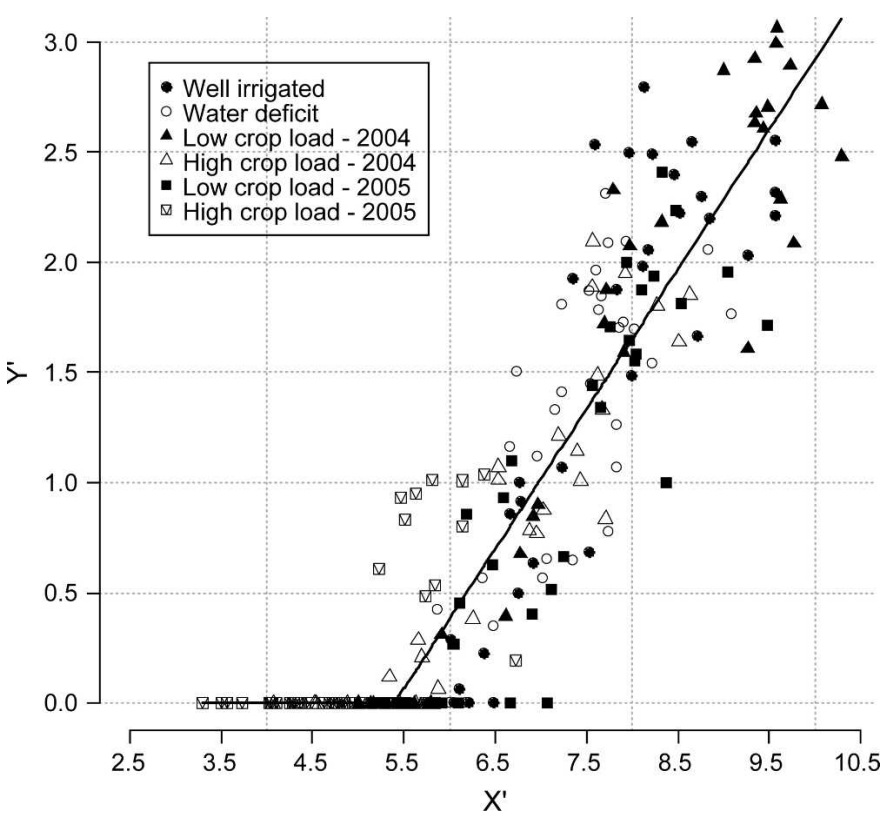

Fig. 8. Relationship between the density of cuticular crack data and the fruit fresh weight data, after being power-transformed $\left[\left(Y^{\prime}=Y^{\lambda},\left[\%^{\lambda}\right]\right)\right.$ and $\left(X^{\prime}=X^{\lambda}\right.$, $\left.\left[g^{\lambda}\right]\right)$, respectively], for 'Zephir' nectarine fruit. Data were transformed using the Box-Cox method $(\lambda=0.41)$. The dark line represents the relationship $Y^{\lambda}=1_{\left\{X^{\lambda} \geq a\right\}} \times b \times\left(X^{\lambda}-a\right)$, with $a=5.396\left[g^{\lambda}\right]$ and $b=0.635\left[(\% / g)^{\lambda}\right]$.

appeared after 106 DAFB. Besides, the low crop load in 2004 increased the cuticular crack surface area per fruit surface area by $66 \%$ and by $95 \%$ in 2005 , in comparison with the fruit from high crop loads. This is consistent with studies on peach-pit splitting (Claypool et al., 1972) and tomato fruit cracking (Peet, 1992; Peet and Willits, 1995), where a positive correlation was observed between fruit splitting and abundant irrigation. Moreover, Opara and Tadesse (2000) obtained a similar reduction of splitting incidence on 'Pacific Rose' apple by withholding irrigation for 6-7 weeks before harvest, as well as a significant increase in splitting of $>60 \%$ with low crop load. Likewise, a high ratio of leaves per fruit contributed to significantly increase the number of tomato fruit affected by microcracking (Ehret et al., 1993). In our experiments, the cuticular crack surface area per fruit surface area was shown to be positively correlated to the fruit fresh weight independently of the fruit growing conditions, but the relationship showed a large fruit-tofruit variation. Therefore, factors other than the fresh weight per se could explain the occurrence of cuticular cracks.

Indeed, varying orchard practices changes the fruit water balance. McFadyen et al. (1996) showed that peach trees carrying heavy crop loads had lower fruit water potential, higher fruit osmotic potential, and, thus, lower fruit turgor potential in comparison with trees carrying light crop loads. The internal turgor pressure acting on the fruit skin would constitute a driving force in the fruit cracking process, as suggested by Sekse (1995). However, contradictions persist when demonstrating a relationship between threshold cracking turgor and cuticular cracks (Leshem et al., 2003). Indeed, cuticular cracks cannot be easily explained by only one variable because we are obviously dealing with a complex phenomenon that also involves physiological explanations, such as the epidermal cell organization, the variability in the cuticle deposition [mainly outside of the epidermal cells or enclosing 
most of the cells (Keren-Keiserman et al., 2004)], and the imbalance between wax production, deposition of cuticle, and fruit growth [Ise (1999) for 'Kensington Pride' mango (Mangifera indica L.); Knoche and Peschel (2006) and Knoche et al. (2004) for sweet cherry fruit]. For instance, irrigation regimes were shown to affect the cuticle thickness and organization in 'O'Henry' peach with a thinner epidermis for excessively irrigated fruit (Crisosto et al., 1994). Similarly, epidermis tensile strength was shown to play a role in fruit cracking control in litchi [Litchi chinensis Sonn. (Huang et al., 1999)]. For sweet cherry fruit, it was well established that the cuticle is highly strained during the final fruit swelling in the absence of cuticular deposition (Knoche et al., 2004). Moreover, the frequency of microcracks on exocarp segments was shown to increase with strain and low vapor pressure deficit (Knoche and Peschel, 2006). These factors constitute the mechanistic basis explaining the effect of irrigation or crop load on cuticular cracking of nectarine fruit.

In summary, by varying the growing conditions of nectarine fruit either by crop load or irrigation regimes, cuticular crack occurrence and development strongly differed. Cuticular cracks appeared during rapid fruit growth. They were densely distributed on the stylar end and peduncle, although the contribution of these zones to the total fruit cuticular crack surface area was low in comparison with the cheeks. By decreasing fruit growth during this critical period, the cuticular crack development was limited. The density of cuticular cracks was shown to be positively related to fruit fresh weight. These results should be considered both in economic and agronomical considerations in the future, from the perspective of integrated horticultural production.

\section{Literature Cited}

Aloni, B., L. Karni, I. Rylski, Y. Cohen, Y. Lee, M. Fuchs, S. Moreshet, and C. Yao. 1998. Cuticular cracking in pepper fruit. I. Effects of night temperature and humidity. J. Hort. Sci. Biotechnol. 73:743-749.

Bakker, J.C. 1988. Russeting (cuticle cracking) in glasshouse tomatoes in relation to fruit growth. J. Hort. Sci. 63:459-463.

Beyer, M., S. Peschel, M. Knoche, and M. Knörgen. 2002. Studies on water transport through the sweet cherry fruit surface: IV. Regions of preferential uptake. HortScience 37:637-641.

Box, G.E.P. and D.R. Cox. 1964. An analysis of transformations. J. R. Stat. Soc. Ser. B 26:211-246.

Børve, J., L. Sekse, and A. Stensvand. 2000. Cuticular fractures promote postharvest fruit rot in sweet cherries. Plant Dis. 84:1180-1184.

Christensen, J.V. 1972. Cracking in cherries: IV. Physiological studies of the mechanism of cracking. Acta Agr. Scand. 22:153-162.

Christensen, J.V. 1973. Cracking in cherries: VI. Cracking susceptibility in relation to the growth rhythm of the fruit. Acta Agr. Scand. 23:52-54.

Claypool, L.L., K. Uriu, and P.F. Lasker. 1972. Split-pit of 'Dixon' cling peaches in relation to cultural factors. J. Amer. Soc. Hort. Sci. 97:181-185.

Considine, J. and K. Brown. 1981. Physical aspects of fruit growth: theoretical analysis of distribution of surface growth forces in fruit in relation to cracking and splitting. Plant Physiol. 68:371-376.

Crisosto, C.H., R.S. Johnson, J.G. Luza, and G.M. Crisosto. 1994. Irrigation regimes affect fruit soluble solids concentration and rate of water loss of 'O'Henry' peaches. HortScience 29:1169-1171.

Ehret, D.L., T. Helmer, and J.W. Hall. 1993. Cuticle cracking in tomato fruit. J. Hort. Sci. 68:195-201.

Faust, M. and C.B. Shear. 1972. Fine structure of the fruit surface of three apple cultivars. J. Amer. Soc. Hort. Sci. 97:351-355.
Glenn, G. and B.W. Poovaiah. 1989. Cuticular properties and postharvest calcium applications influence cracking of sweet cherries. J. Amer. Soc. Hort. Sci. 114:781-788.

Huang, X.M., H.C. Wang, F.F. Gao, and H.B. Huang. 1999. A comparative study of the pericarp of litchi cultivars susceptible and resistant to fruit cracking. J. Hort. Sci. Biotechnol. 74:351-354.

Ise, B. 1999. Changes in the cuticular surface during the development of mango (Mangifera indica L.) cv. Kensington Pride. Scientia Hort. 79:13-22.

Jobin-Lawler, F. 2005. Effet préventif d'une pulvérisation de bore et de calcium sur l'incidence et la sévérité du microfendillement de la tomate de serre. Faculté des Sciences de l'Agriculture et de l'Alimentation, Université Laval, Québec, Canada. MS Thesis.

Keren-Keiserman, A., Z. Tanami, O. Shoseyov, and I. Ginzberg. 2004. Differing rind characteristics of developing fruits of smooth and netted melons (Cucumis melo). J. Hort. Sci. Biotechnol. 79:107113.

Knoche, M. and S. Peschel. 2006. Water on the surface aggravates microscopic cracking of the sweet cherry fruit cuticle. J. Amer. Soc. Hort. Sci. 131:192-200.

Knoche, M., M. Beyer, S. Peschel, B. Oparlakov, and M.J. Bukovac. 2004. Changes in strain and deposition of cuticle in developing sweet cherry fruit. Physiol. Plant 120:667-677.

Knoche, M., S. Peschel, and M. Hinz. 2002. Studies on water transport through the sweet cherry fruit surface: III. Conductance of the cuticle in relation with fruit size. Physiol. Plant. 114: 414-421.

Knoche, M., S. Peschel, M. Hinz, and M.J. Bukovac. 2001. Studies on water transport through the sweet cherry fruit surface: II. Conductance of the cuticle in relation to fruit development. Planta 213:927-936.

Leshem, Y., A. Nerd, and Y. Mizrahi. 2003. Fruit cracking in Cereus peruvianus, a new cactus crop. J. Hort. Sci. Biotechnol. 78:426-431.

Matas, A.J., G. Lopez-Casado, J. Cuartero, and A. Heredia. 2005. Relative humidity and temperature modify the mechanical properties of isolated tomato fruit cuticles. Amer. J. Bot. 92:462-468.

McFadyen, L.M., R.J. Hutton, and E.W.R. Barlow. 1996. Effects of crop load on fruit water relations and fruit growth in peach. J. Hort. Sci. 71:469-480.

Milad, R.E. and K.A. Shackel. 1992. Water relations of fruit end cracking in 'French' prune (Prunus domestica L. cv. French). J. Amer. Soc. Hort. Sci. 117:824-828.

Nguyen-The, C. 1991. Structure of epidermis wall, cuticle and cuticular microcracks in nectarine fruit. Agronomie 11:909-920.

Nguyen-The, C., R. Hugueney, and M. Arnoux. 1989. Contribution à l'étude des voies de pénétration de parasites fongiques des nectarines Monilia laxa (Ascomycète-Discomycète) et Rhizopus stolonifer (Zygomycète-Mucorale). Agronomie 9:271-276.

Ohta, K., T. Hosoki, K. Matsumoto, M. Ohya, N. Ito, and K. Inaba. 1997. Relationships between fruit cracking and changes of fruit diameter associated with solute flow to fruit in cherry tomatoes. J. Jpn. Soc. Hort. Sci. 65:753-759.

Opara, L.U., A.J. Hodson, and C.J. Studman. 2000. Stem-end splitting and internal ring-cracking of 'Gala' apples as influenced by orchard management practices. J. Hort. Sci. Biotechnol. 75: 465-469.

Opara, L.U., C.J. Studman, and N.H. Banks. 1997. Fruit skin splitting and cracking. Hort. Rev. (Amer. Soc. Hort. Sci.) 19:217-262.

Opara, L.U. and T. Tadesse. 2000. Calyx-end splitting and physicochemical properties of 'Pacific Rose' TM apple as affected by orchard management factors. J. Hort. Sci. Biotechnol. 75:581-585.

Peet, M.M. 1992. Fruit cracking in tomato. HortTechnology 2:216-223.

Peet, M.M. and D.H. Willits. 1995. Role of excess water in tomato fruit cracking. HortScience 30:65-68.

Peschel, S. and M. Knoche. 2005. Characterization of microcracks in the cuticle of developing sweet cherry fruit. J. Amer. Soc. Hort. Sci. 130:487-495. 
Petracek, P.D. and M.J. Bukovac. 1995. Rheological properties of enzymatically isolated tomato fruit cuticle. Plant Physiol. 109: 675-679.

Sekse, L. 1995. Fruit cracking in sweet cherries (Prunus avium L.). Some physiological aspects-A mini review. Scientia Hort. 63:135-141.

Sekse, L. 1998. Fruit cracking mechanisms in sweet cherries (Prunus avium L.)-A review. Acta Hort. 468:637-648.

Veraverbeke, E.A., P. Verboven, P. Van Oostveldt, and B.M. Nicolaï. 2003. Prediction of moisture loss across the cuticle apple (Malus sylvestrissubsp. mitis (Wallr.)) during storage. Part 1. Model devel- opment and determination of diffusion coefficients. Postharvest Biol. Technol. 30:75-88.

Verner, L. and E.C. Blodgett. 1931. Physiological studies of the cracking of sweet cherries. Univ. Idaho Agr. Expt. Sta. Bul. 184:1-15.

Wiedemann, P. and C. Neinhuis. 1998. Biomechanics of isolated plant cuticles. Bot. Acta 111:28-34.

Yamamoto, T., K. Hosoi, and S. Watanabe. 1990. Relationship between the degree of fruit cracking of sweet cherries and the distribution of surface stress of the fruit analysed by a newly developed system. J. Jpn. Soc. Hort. Sci. 59:509-517. 